\title{
EDITORIAL
}

\section{Message from the Chief Editor}

\section{Shoji Sonoda ${ }^{1}$}

Published online: 18 March 2020

(c) The Japanese Society of Applied Entomology and Zoology 2020

The Chief Editor of Applied Entomology and Zoology is pleased to announce a new journal feature, Editors' Choice. A few articles selected as highlights of each publishing year will be published as Editors' Choice with open access. Editors' Choice papers describe high quality research or innovative experimental procedures in applied entomology, applied zoology and related fields. Editors' Choice papers may also include submissions describing studies on extremely timely topics in applied entomology, applied zoology and related fields, especially focusing on plant protection. Review articles dealing with defined topics that are highly novel and of particular interest to the readership of Applied Entomology and Zoology may also be considered as Editors' Choice papers. Authors are encouraged to indicate whether their submission meets the requirements of an Editors' Choice paper. However, the final selection of these papers is the exclusive prerogative of the Applied Entomology and Zoology Editorial Board, and is approved by the Handling Associate Editors and the Chief Editor.

Shoji Sonoda

Chief Editor

Applied Entomology and Zoology

Publisher's Note Springer Nature remains neutral with regard to jurisdictional claims in published maps and institutional affiliations.

Shoji Sonoda

sonodas@cc.utsunomiya-u.ac.jp

1 Utsunomiya University, Utsunomiya, Japan 